\title{
Espíritu e Iglesia en Francisco
}

\author{
Spirit and Church in Francis
}

Victor Codina

\section{Resumen}

El artículo muestra que el Papa Francisco no es un teólogo profesional, pneumatólogo o eclesiólogo, sino pastor y profeta, preocupado por la reforma de la Iglesia, tanto hacia dentro (conversión, cambio de estructuras) como hacia fuera (misión y evangelizacíón), con un estilo pastoral mariano.

Palabras clave: Cátedra magisterial. Cátedra pastoral. Reforma. Pastoral mariana.

\section{Abstract}

The paper demonstrates that Pope Francis is not a professional pneumatological or ecclesiological theologian, but a pastor and prophet, concerned with the reformation of the Church, as much focused within (conversion, change of structures) as toward the outside (mission and evangelization), with a Marian pastoral style.

Keywords: Magisterial Chair. Pastoral Chair. Reform. Marian pastoral.

\section{Introducción}

Como punto de partida y enfoque de esta exposición quisiera recordar un texto conocido de Tomás de Aquino en el que reconoce la existencia de dos cátedras: la cathedra pastoralis de los que ejercen el ministerio ordenado 
jerárquico en la Iglesia, singularmente los obispos y la cathedra magistralis de los teólogos y doctores. ${ }^{1}$ Ambos magisterios no son paralelos sino convergentes, a veces se identifican (como en muchos Padres de la Iglesia), aunque entre los dos magisterios ha habido siempre tensiones que, según Newman, bien llevadas conducen a un muto equlibrio.

Esto supuesto, aunque Jorge Bergoglio había enseñado pastoral en la Facultad de los jesuitas de San Miguel, Buenos Aires, el Papa Francisco no es un teólogo académico profesional, no ejerce la cátedra magisterial sino la cátedra pastoral.

\section{Franciso no es Pneumatólogo ni eclesiólogo}

Por tanto no elabora una Pneumatología bíblica, patrística y sistemática al estilo de Congar, Hilberath, H.Mühlen, Durrwell, Sesboüé, Comblin, Boff.

Tampoco escribe una eclesiología académica, como las de Kasper, Küng, Rahner, Ratzinger, Lohfink, Congar, Tillard, França Miranda, Pie-Ninot, Hoornaert, Boff.

Ni establece una reflexión histórica y teológica sobre la relación entre Espíritu y la Iglesia, por ejemplo a partir del tercer artículo del Credo, como hacen Nautin y De Lubac.

No reacciona teológicamente ante la acusación de los teólogos orientales de "cristomonismo", 2 es decir de que la Iglesia latina-romana está centrada casi exclusivamente en Cristo, lo cual, según ellos, hace que la libertad profética, la divinización de la humanidad, la dignidad adulta y regia del laicado y el nacimiento de la nueva criatura, queden sustituidos por la institución jerárquica de la Iglesia, plasmada en términos de poder y sumisión. ${ }^{3}$

Ni comenta la relación entre el Espíritu Santo y la Iglesia en la conocida formulación del Metropolita Ignacio Hazim, posteriormente Patriarca oriental Ignacio IV de Antioquía, pronunciada en la IV Asamblea del Consejo mundial de Iglesias de Upsala en 1968:

El Espíritu Santo es, personalmente, la Novedad en acción en el mundo,

\footnotetext{
${ }^{1}$ Quodlibet III, 9, ad 3; In IV Sent, d 19,2,2, 1 qa 2, ad 2.

2 NISSIOTIS, N. "Pneumatologie orthodoxe". En: LEENHARDT, F. J.; REYMOND P.; FRAENKEL, P.; NISSIOTIS, N. A.; WIDMER, G.; SENARCLENS, J.; ROCHEDIEU, E. Le Saint Esprit. Genève: Labor et Fides, 1963, pp. 85-105.

${ }_{3}$ EVDOKIMOV, P. La connaisance de Dieu selon la tradition orientale. Lyon: Mappus, 1967, p. 146.
} 
es la Presencia del Dios-con-nosotros, junto a nuestro Espíritu $(\mathrm{Rm} 8,16)$. Sin Él, Dios queda lejos, Cristo permanece en el pasado, el evangelio es letra muerta, la Iglesia es una pura organización, la autoridad es tiranía, la misión es propaganda, la liturgia es mero recuerdo, la vida cristiana es una moral de esclavos.

Pero en el Espíritu, y en una sinergia indisociable, el cosmos es liberado y gime en el alumbramiento del Reino, el hombre lucha contra la "carne", Cristo resucitado está aquí, el evangelio es una fuerza vivificadora, la Iglesia significa la comunión trinitaria, la autoridad es un servicio liberador, la misión es un Pentecostés, la liturgia es memorial y anticipación, la acción humana es divinizada. $^{4}$

Tampoco investiga cuándo se pasó de la Iglesia comunidad de Cristo y del Espíritu, con diferentes dones y carismas, a la eclesiología vertical y piramidal de Dios-Cristo-Iglesia-Papa, sin mención del Espíritu; ni cuándo, retomando la imagen de Ireneo de las dos manos del Padre, la Iglesia latina poco a poco se olvidó la mano del Espíritu y afirmó solamente la mano del Hijo, visible e histórica, que se prolonga en la Iglesia visible, sobre todo en la jerarquía.

Por tanto no estudia cómo se va ocultando la misión del Espíritu en la teología latina: en la escolástica el don de Espíritu es sustituido por la gratia capitis Christi, desaparece la epíclesis eucarística y se acentúa el relato consecratorio, los himnos litúrgicos medievales sobre el Espíritu son más individualistas que eclesiales ("dulce huésped del alma") y los primeros tratados de eclesiología (de Jaime de Viterbo y Egidio de Roma, en el s XIV) son tratados sobre el poder del Papa frente al poder del emperador. Ni comenta la afirmación del Cardenal Roberto Belarmino de que la Iglesia es una sociedad tan visible e histórica como el Reino de los francos o la República de Venecia.

Tampoco explora teológicamente la evolución histórica de los calificativos del Obispo de Roma, cuando se pasa de Vicario de Pedro y Siervo de los siervos de Dios a Vicario de Cristo, Jefe de la Iglesia y Vicario de Dios, todo lo cual tiene connotaciones y consecuencias no solo eclesiales sino políticas. ${ }^{5}$

No aborda el tema del Filioque que se añadió por parte de Roma en el credo Niceno-constantinopolitano, es decir que el Espíritu procede del Padre y

\footnotetext{
${ }^{4}$ HAZIM, I. La résurrection et l'homme d'aujourd'hui. Beyrouth-Liban: Editions An- Nour, 1970, reproducido en Irénikon 42 (1968), pp. 344-356.

${ }^{5}$ Inocencio IV concede a los reyes de España y Portugal conquistar los territorios de América y establece los límites entre ambos reinos (Tratado de Tordesillas, 1494).
} 
del Hijo, lo cual provocó la protesta del Oriente porque veía en el Filioque una marginación apendicular del Espíritu en la Trinidad. ${ }^{6} \mathrm{Ni}$ se pronuncia sobre la sugerencia que proponen teólogos orientales como Paul Evdokimov y Olivier Clément y algunos católicos como F. X. Durrwell de completar el Filioque con el Spirituque, es decir, que el Hijo es engendrado por el Padre y el Espíritu.

No menciona que el vacío del Espíritu se llenó y compensó con algunos sucedáneos teológicos y pastorales, como el Papa, María y la eucaristía, "tres realidades blancas", que aunque son irrenunciables para la fe cristiana, no pueden sustituir al Espíritu, como afirma Congar. ${ }^{7}$

Tampoco comenta textos del Vaticano II como la afirmación de que la Iglesia de Cristo es humana y divina y subsiste en la Iglesia católica (LG 8).

En resumen, Francisco no está preocupado por cuestiones y definiciones abstractas y teóricas sobre Espíritu e Iglesia, sino que asume la Pneumatología y la Elesiología del Vaticano II (LG I y II), la Iglesia como Pueblo de Dios suscitado y guiado por el Espíritu. Esta teología del Pueblo de Dios, influenciada ciertamente por la teología argentina de Lucio Gera y Carlos María Galli, como han demostrado Juan Carlos Scannone, Felipe Luciani, Virginia Azcuy, etc es la que se refleja en los escritos y actuaciones de Francisco, ${ }^{8}$ sin que él asuma ni pretenda imponer la teología argentina a toda la Iglesia. Él distingue claramente el magisterio teológico del magisterio pastoral.

Podemos resumir el camino recorrido hasta ahora afirmando que Francisco no elabora ni una Pneumatología ni una Eclesiología sistemáticas ni tampoco una reflexión teológica académica sobre la relación entre Espíritu e Iglesia. Por esto hemos de explorar otras vías de comprensión.

\section{Pastor y profeta}

Francisco más que profesor académico es ante todo un pastor y un profeta. Su cátedra es la cátedra pastoral.

Parte de la realidad eclesial y social, ya que como él afirma: "la realidad

\footnotetext{
${ }^{6}$ Cf. CODINA, V. Los caminos del Oriente cristiano. Santander: Sal Terrae, 1997.

${ }^{7}$ CONGAR, Y. El Espíritu Santo. Barcelona: Herder, 1983, pp. 189-194.

${ }^{8}$ Cf. SCANNONE, J. C. La teología del pueblo. Santander: Sal Terrae, 2016; LUCIANI, F. El Papa Francisco y la teología del Pueblo. Madrid: PPC, 2016; GERA, L. La teología argentina del Pueblo. Edición de Virgínia R. Azcuy. Santiago: Ediciones Universidad Alberto Hurtado, 2015. Cf. también el n ${ }^{\circ} 168$ de la revista del CELAM, Medellín, todo él dedicado al Papa Francisco (VV.AA. “Francisco ¡Tú eres Pedro!”. Medellín 168 (2017), pp. 285-590).
} 
es más importante que la idea" (EG 231-333) y si no se parte de la realidad hay el riesgo de caer en peligrosas ideologizaciones y nominalismos.

Las preguntas que inquietan a Francisco parten de la realidad actual. Seguramente Francisco se pregunta por qué la Iglesia de hoy, en lugar de ser un signo de credibilidad, como afirmaba Vaticano I (DH 3013), se ha convertido en signo de contradicción y es para muchos el mayor obstáculo para aceptar y vivir la fe cristiana. El repetido axioma de muchos cristianos "Jesús sí, Iglesia no", expresa una profunda desafección eclesial que conduce para muchos a vivir "una creencia sin pertenencia" (Grace David) o a una pertenencia parcial (J. de Dios Martín Velasco) y en último término a buscar una espiritualidad sin dogmas, sin creencias, sin religión y sin dioses (M. Corbí).

Hay en muchos sectores católicos un rechazo a una Iglesia piramidal, que se considera Civitas Dei, Mater et magistra, el Reino de Dios en la tierra, con una dicotomía entre la Ecclesia docens y la Ecclesia discens, dicotomía que refleja una profunda división entre jerarquía y laicado, con miedo a la opinión pública en la Iglesia, con poco respeto a los derechos humanos en el seno de la misma Iglesia.

Hoy muchos católicos critican el centralismo y patriarcalismo de la jerarquía latina, sus ansias de dominación y prepotencia, su poder revestido de un carácter sagrado (la jerarquía), se cuestiona el "tinglado" y pirámide institucional, y su parafernalia eclesiástica que alcanza su máxima expresión simbólica en el Estado Vaticano con su himno, su bandera y la pintoresca guardia suiza; a ello se une una crítica generalizada de la Curia vaticana, por su falta de transparencia económica y el ocultamiento de los escándalos sexuales del clero.

Produce la impresión de que el poder de la organización eclesial ha opacado gran parte del carisma, como denunció Leonardo Boff en su controvertido libro Iglesia carisma y poder. $^{9}$

Ciertamente el Vaticano II intentó una Reforma eclesial, un réssourcement $\mathrm{y}$ un aggiornamento pero en el postconcilio se frenaron muchas de sus intuiciones conciliares sobre el Pueblo de Dios, colegialidad, laicado, ecumenismo, libertad religiosa, diálogo inter-religioso... y se incidió en una nueva centralización de la Sede apostólica, en rigidez moral y control teológico.

Podemos preguntarnos también si las palabras de Benedicto XVI en su

${ }_{9}^{9}$ BOFF, L. Carisma y poder. Santander: Sal Terrae, 1982. 
admirable y lúcida dimisión del Papado, "Ya no tengo más fuerzas", además de confesar la debilidad de su avanzada edad, no son en el fondo una tácita confesión del fracaso del estilo actual de la Iglesia como organización de poder jerárquico. En esta situación ¿cómo transmitir la fe, o mejor, cómo iniciar a una mistagogía a las nuevas generaciones?

Todo ello no solo es consecuencia de algunos fallos humanos de ciertos individuos, sino que es el resultado de unas estructuras y de una teología alejada no solo de la sensibilidad democrática moderna sino de sus fuentes evangélicas.

La Iglesia de Jesús es ciertamente una comunidad visible e histórica, no es algo invisible y puramente interior, ya que como todo grupo social necesita organización, estructuras y gobierno. La Iglesia no puede evadir las leyes de la antropología y de la sociología, porque todo ser humano se desarrolla en una comunidad previamente existente y toda verdad, valor o carisma necesita una cierta institucionalización si quiere perdurar en el tiempo. Por esto la Iglesia necesita elaborar doctrinas, celebraciones y normas.

Además, desde la fe cristiana, la lógica de la encarnación conlleva la necesidad de mediaciones humanas salvíficas para que la salvación de Jesús pueda llegar a todos los pueblos y culturas. Lumen Gentium 9 lo expresa claramente:

En todo tiempo y lugar son aceptos a Dios los que le temen y practican la justicia (cf. Hch 10, 35). Quiso, sin embargo, el Señor santificar y salvar a los hombres no individualmente y aislados entre sí, sino constituir un pueblo que le conociera en la verdad y lo sirviera santamente.

Esto explica la elección del pueblo de Israel, preparación de lo que se realizó en Cristo y que se prolonga en la Iglesia. El Nuevo Testamento ya nos ofrece la experiencia de Jesús a través de una primera institucionalización de la fe cristiana.

Pero, por otra parte, la institución eclesial, como toda mediación humana, es histórica y está sujeta a las culturas y por tanto debe revisarse continuamente para responder a su finalidad que es que las personas, a través de su mediación, accedan al Misterio último inefable y salvífico que llamamos Dios. Como dice Sto. Tomás, la fe cristiana no termina en el enunciado doctrinal sino en la realidad expresada. La Iglesia es ante todo una comunidad mistagógica.

A todo ello hay que añadir que toda institución, también la Iglesia, lleva siempre la marca del pecado, pecado individual pero que también se estructura e incrusta en las mediaciones religiosas y eclesiales que se hipertrofian y se 
absolutizan, degenerando en dogmatismo, moralismo y juridicismo, en una jerarquización centralista e impositiva. ${ }^{10}$ De ahí la urgencia pastoral del axioma Ecclesia semper reformanda, la necesidad de una continua reforma como afirmó Vaticano II en su Decreto sobre ecumenismo (UR 6).

Frente a esta difícil y crítica situación, Francisco no quiere reforzar ni acentuar lo dogmático, lo jurídico y lo moral, sino que realiza un cambio de paradigma pastoral: pasa del dogma al kerigma y a la mistagogía; pasa del moralismo al discernimiento y a la misericordia; pasa de Pneumatología a la espiritualidad; de la Eclesiología a una nueva eclesialidad, a un nuevo estilo de Iglesia, más acorde al estilo de Jesús de Nazaret. Es la revolución de la ternura, del amor y de la misericordia (W. Kasper).

Lo que Francisco pretende no es defender o propagar una nueva Pneumatología ni una nueva Eclesiología, ni la conexión entre ambas, sino reformar la Iglesia, tanto hacia dentro como hacia fuera. La Pneumatología y la Eclesiología pastoral de Francisco son proféticas y se resumen en la palabra: reforma.

\section{La Reforma eclesial}

Y. M. Congar que publicó antes del concilio un famoso libro sobre verdaderas y falsas reformas de la Iglesia, ${ }^{11}$ resume en cuatro puntos las condiciones para una verdadera reforma eclesial:

$1^{\circ}$ Primacía de la caridad y de la pastoral frente a una postura teórica, ideológica y abstracta. No querer hacer otra Iglesia sino hacer que la Iglesia sea otra, que se renueve la única Iglesia de Jesús.

$2^{\circ}$ Mantener la comunión con el conjunto eclesial, con el centro y la periferia, con la Urbs y el Orbis, no actuar en solitario sino como parte de la Iglesia, agere ut pars.

$3^{\text {o }}$ Tener paciencia, evitar apremios y acciones violentas, pero no vacilar en lo ya decidido ni exasperar a los que padecen las urgencias de los cambios. Se requiere tiempo y sabiduría para hacer avanzar la reforma.

\footnotetext{
${ }^{10}$ FRANÇA MIRANDA, M. "Instituição e indivíduo na Reforma eclesial de Lutero e de Francisco". Perspectiva Teológica 1 (2017), pp. 17-40.

${ }^{11}$ CONGAR, Y. Verdaderas y falsas reformas en la Iglesia. Madrid: Instituto de Estudios políticos, 1973 (el original francés es de 1950).
} 
$4^{\circ}$ Una verdadera renovación para llegar a la tradición profunda y no introducir novedad de forma mecánica. Una vuelta a las fuentes, a lo originario y fundacional.

¿Cómo concreta Francisco esta reforma? ¿Será Francisco heredero del concepto ignaciano de reforma?

El Papa Francisco ha abierto las puertas y ventanas de la Iglesia al viento del Espíritu y prolonga la reforma del Vaticano II. En su corto pontificado se pueden ya apreciar cambios eclesiales, no solo en sus documentos magisteriales sino a través de sus gestos y símbolos: presentarse en su primera alocución al pueblo como obispo de Roma, no residir en los Palacios Vaticanos, comer con mendigos, obreros y presos, abrazar a discapacitados y enfermos, visitar lugares de refugiados como Lampedusa y Lesbos, diálogo con periodistas en el avión de regreso de sus viajes, etc. En Evangelii gaudium dedica muchas páginas (135-175) para tratar de la homilía, un tema realmente pastoral que otros documentos del magisterio no habían abordado.

La reforma de Francisco tiene dos objetivos uno ad intra, conversión personal y estructural de la Iglesia y otro ad extra conversión a la misión evangelizadora. Pero ambos aspectos están tan estrechamente unidos que difícilmente se pueden separar.

Hay un cambio de imagen eclesial, un tránsito de un estilo eclesial a otro estilo eclesial, todo ello bajo la órbita del Espíritu. El Espíritu es el agente reformador de la Iglesia.

Enumeremos, a modo de decálogo, algunos de los rasgos más significativos de esta reforma eclesial:

1. De una Iglesia poderosa, distante, fría, acartonada, miedosa, reaccionaria, de la cual la gente se aleja y la abandona... al sueño de una Iglesia pobre, sencilla, cercana, acogedora, sincera, realista, que promueve la cultura del encuentro y la ternura. El nuevo obispo de Roma, Francisco se reconoce pecador y pide oraciones; recuerda que la Iglesia necesita una conversión y una continua reforma evangélica, una reforma a lo Francisco de Asís.

2. De una Iglesia moralista obsesionada por el aborto, el control de natalidad, el matrimonio homosexual... a una Iglesia que va a lo esencial, que se centra en Jesucristo contemplado y adorado, recupera el evangelio, anuncia la gran buena noticia de la salvación 
en Cristo, pues Jesús es lo único que atrae, una Iglesia que difunda el olor del evangelio de Jesús. No puede ser un cristianismo de meras devociones sin Jesús. La alegría del evangelio llena el corazón de todos los que se encuentran con Jesús (Evangelii gaudium).

3. De una Iglesia centrada en el pecado y que ha hecho del sacramento de la confesión una tortura y ha convertido la petición de los sacramentos en una aduana inquisitorial... a una Iglesia de la misericordia de Dios, de la ternura, de la compasión, con entrañas maternales, que refleje la misericordia del Padre, una Iglesia ante todo hospital de campaña que cure heridas de emergencia, que cuide la creación (Laudato si), una Iglesia en la que los sacramentos sean para todos, no solo para los perfectos.

4. De una Iglesia autorreferencial, preocupada por el proselitismo...a una Iglesia de los pobres preocupada ante todo del dolor y del sufrimiento humano, de la guerra, del hambre, del paro juvenil, de los ancianos, donde los últimos sean los primeros, donde no se sirva a Dios y al dinero; una Iglesia profética, libre ante los poderes de este mundo; en Evangelii gaudium (53-60) afirma que el actual sistema económico basado en la idolatría del dinero es injusto, pues enriquece a unos pocos y convierte a una gran mayoría en masas sobrantes, es un sistema excluyente que mata; por esto lanza un "no" a una economía de exclusión, un "no" a la nueva idolatría del dinero, un "no" al dinero que gobierna en lugar de servir, un "no" a la inequidad que genera violencia. Sus mensajes desde Lampedusa y Lesbos son un llamado a la conversión, a responder la pregunta de Yahvé a Caín: Caín ¿qué has hecho de tu hermano?

5. De una Iglesia encerrada en sí misma, reliquia del pasado, con tendencia a mirarse el ombligo, con sabor a invernadero, que espera que vengan los otros... a una Iglesia que sale a la calle, está en salida, "callejea la fe", va los márgenes sociales y existenciales, a las fronteras, a los que están lejos, aun con riesgo de tener accidentes; no teme ser una Iglesia minoritaria y pequeña, con tal que sea semilla y levadura, que abra caminos nuevos, que vaya sin miedo a servir, una Iglesia a la intemperie, que sale a las cunetas del mundo, una Iglesia en estado de misión.

6. De una Iglesia que discrimina a los que piensan diferente, a los 
diversos, a los otros... a una Iglesia que respeta a los que siguen su propia conciencia, a las Iglesias y a otras religiones, a los ateos, a los homosexuales, dialoga con no creyentes, con los judíos, "nuestros hermanos mayores", una Iglesia de puertas abiertas, atenta a los nuevos signos de los tiempos, que invita al discernimiento pastoral como aparece sobre todo en el capítulo VIII de Amoris laetiia, donde Francisco no cuestiona la indisolubilidad del matrimonio pero promueve una pastoral de la misericordia que pasa del semáforo, rojo o verde, a la brújula del discernimiento y de la conciencia ( $\mathrm{J}$. Masiá).

7. De una Iglesia con tendencia restauracionista y de vuelta atrás, que añora el pasado... a una Iglesia que considera que el Vaticano II es irreversible, que hay que implementar sus intuiciones sobre la colegialidad y la sinodalidad, evitar el centralismo y el autoritarismo en el gobierno, caminar en medio de las diferencias. El Papa reconoce que no tiene la respuesta a todas las cuestiones, que hay que reformar el Papado, que hay que dar responsabilidad a los laicos, ofrecer mayor protagonismo a la mujer, desclericalizar la Iglesia, pues el clericalismo no es cristiano. Francisco alerta a la Curia romana pero también a las diócesis, parroquias y comunidades religiosas de no caer en la tentación de sentirse imprescindibles, el carrerismo, los intereses mundanos, el deseo de riquezas, la insensibilidad ante los problemas ajenos, la burocracia, el Alzheimer espiritual, etc.

8. De una Iglesia con pastores encerrados en sus parroquias, clérigos de despacho, que hacen colección de antigüedades y buscan hacer carrera,.. a pastores que huelan a oveja, que caminen delante, detrás y en medio del pueblo; el carrerismo es la lepra del Papado, la curia es vaticano-céntrica y fácilmente traslada su visión al mundo. Los cardenales no son "príncipes de la Iglesia" sino servidores del pueblo.

9. De una Iglesia envejecida, triste, con cara de funeral y de cuaresma sin Pascua... a una Iglesia joven y alegre, levadura y fermento en la sociedad, con la alegría y la libertad del Espíritu, con luz y transparencia, sin nada que ocultar.

10. De una Iglesia ONG piadosa, clerical, machista, monolítica, narcisista, con pesimismo, cansancio, desánimo, fatalismo, desilusión, acedia egoísta y finalmente mundanidad espiritual ... a una Iglesia Casa y 
Pueblo de Dios, mesa más que estrado, que respete la diversidad, donde jueguen un papel relevante los laicos, las mujeres y las familias.

\section{Conclusión}

La reforma de Francisco es fruto del nuevo paradigma pastoral que fomenta la espiritualidad y otra forma de ser Iglesia: otra Iglesia es posible. Si no queremos que la misión sea una mera propaganda o marketing publicitario sino que la Iglesia sea una comunidad trinitaria y la misión un Pentecostés renovado y prolongado, hemos de fortalecer nuestra fe en el Espíritu del Resucitado que está presente y actuante en la sociedad y en la Iglesia como sacramento del Reino. No podemos ser, como ya advertía Juan XXIII, profetas de calamidades, pues creemos que el Espíritu del Señor llena el universo y guía la historia hacia la escatología final.

Vuelve a renacer hoy una primavera eclesial, Francisco retoma las intuiciones de Juan XXIII y del Vaticano II que durante largos años fueron frenadas. Todo esto es posible por el reencuentro con el Espíritu del Resucitado (Evangelii gaudium capítulo V).

Francisco no elabora una Pneumatología teórica, sino que pone la reforma ad intra y la misión ad extra bajo la órbita del Espíritu que actúa como quiere y donde quiere y siempre viene en ayuda de nuestra debilidad. Hay que confiar en el Espíritu, dejarse llevar con Él, renunciar a calcularlo y controlarlo todo, dejar que Él nos ilumine, guíe, oriente, que nos impulse hacia donde Él quiera, aunque a veces esta confianza en lo invisible nos produzca un cierto vértigo (EG 279-280).

Más concretamente, el encuentro con María (EG 284-288) puede simbolizar la ruta pastoral de Francisco. María aparece como el icono femenino del Espíritu y de la Iglesia. Y todo ello estrechamente enlazado con el caminar del pueblo, pues en medio del pueblo siempre está María (EG 284).Cristo nos lleva a María (EG 285) para que ella continúe con nosotros la revolución de ternura y cariño que comenzó con Jesús, para que camine y luche con nosotros y derrame la cercanía del amor divino (EG 286).

María es para Francisco modelo del itinerario eclesial, es un modelo eclesial (EG 288).El pueblo encuentra en María la ternura femenina de Dios, el rostro materno de la Iglesia, el aliento y consuelo de la Ruah divina, el estilo 
mariano de la evangelización, el don de Jesús al pueblo, el amor y alegría para los pequeños y pobres.

María, mujer del pueblo, simboliza y encarna el nuevo paradigma pastoral de Francisco, su Eclesiología y su Pneumatología. La fe del pueblo y la piedad popular se convierten en un lugar teológico privilegiado (EG 126).

Y todo ello sucede porque el pastor Francisco se ha dejado evangelizar por los pobres. Podemos aplicar a Francisco lo que Don Pedro Casaldáliga le dice a Mons. Romero: "Los pobres te enseñaron a leer el Evangelio".

\section{Referencias bibliográficas}

BOFF, L. Carisma y poder. Santander: Sal Terrae, 1982.

CODINA, V. Los caminos del Oriente cristiano. Santander: Sal Terrae, 1997.

CONGAR, Y. Verdaderas y falsas reformas en la Iglesia. Madrid: Instituto de Estudios políticos, 1973.

DENZINGER, H.; HÜNERMANN, P. El magisterio de la Iglesia: Enchiridion symbolorum definitionum et declarationum de rebus fidei et morum. Barcelona: Herder, 2000.

EVDOKIMOV, P. La connaisance de Dieu selon la tradition orientale. Lyon: Mappus, 1967.

FRANÇA MIRANDA, M. "Instituição e indivíduo na Reforma eclesial de Lutero e de Francisco". Perspectiva Teológica 1 (2017), pp. 17-40.

GERA, L. La teología argentina del Pueblo. Edición de Virgínia R. Azcuy. Santiago: Ediciones Universidad Alberto Hurtado, 2015.

HAZIM, I. La résurrection et l'homme d'aujourd'hui. Beyrouth-Liban: Editions An- Nour, 1970.

HAZIM, I. “La résurrection et l'homme d'aujourd'hui”. Irénikon 42 (1968), pp. 344-356.

LUCIANI, F. El Papa Francisco y la teología del Pueblo. Madrid: PPC, 2016.

NISSIOTIS, N. "Pneumatologie orthodoxe". En: LEENHARDT, F. J.; REYMOND P.; FRAENKEL, P.; NISSIOTIS, N. A.; WIDMER, G.; SENARCLENS, J.; ROCHEDIEU, E. Le Saint Esprit. Genève: Labor et Fides, 1963, pp. 85-105. 
PAPA FRANCISCO. "Amoris laetitia". Disponivel en: < http://w2.vatican. $\mathrm{va} /$ content/francesco/es/apost_exhortations/documents/papa-francesco_ esortazione-ap_20160319_amoris-laetitia.html>. Acesso en 23 de noviembre de 2017.

PAPA FRANCISCO. "Evangelii gaudium”. Disponivel en: $<$ http://w2.vatican.

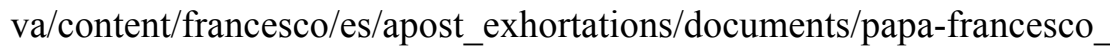
esortazione-ap_20131124_evangelii-gaudium.html>. Acesso en 23 de noviembre de 2017.

PAPA FRANCISCO. "Laudato si"”. Disponivel en: < http://w2.vatican.va/ content/francesco/es/encyclicals/documents/papa-francesco_20150524 enciclica-laudato-si.html>. Acesso en 23 de noviembre de 2017.

SCANNONE, J. C. La teología del pueblo. Santander: Sal Terrae, 2016.

TOMAS DE AQUINO - Quodlibet III, 9, ad 3; In IV Sent, d 19,2,2, 1 qa 2, $\operatorname{ad} 2$.

VATICANO II. "Lumen gentium". Disponivel en: < http://www.vatican. va/archive/hist_councils/ii_vatican_council/documents/vat-ii const_19641121_lumen-gentium_sp.html $>$. Acesso en 23 de noviembre de 2017.

VATICANO II. "Unitatis redintegratio". Disponivel en: < http://www. vatican.va/archive/hist_councils/ii_vatican_council/documents/ vat-ii_decree_19641121_unitatis-redintegratio_sp.html>. Acesso en 23 de noviembre de 2017.

VV.AA. “Francisco ¡Tú eres Pedro!”. Medellín 168 (2017), pp. 285-590.

Víctor Codina

Doctor en Teología por la Universidad Gregoriana de Roma Profesor emérito de la Universidad Católica Boliviana de Cochabamba Cochabamba - Bolivia E-mail: victorcodinasj@gmail.com

Recebido em: 03/10/17

Aprovado em: 27/11/17 